\title{
A Guideline for the Treatment and Prevention of NSAID-Induced Ulcers
}

\author{
Frank L. Lanza, M.D., F.A.C.G. \\ Baylor College of Medicine, Houston, Texas
}

and the Members of the Ad Hoc Committee on Practice Parameters of the American College of Gastroenterology*

\section{PREAMBLE}

Guidelines for clinical practice are intended to indicate preferred approaches to medical problems as established by scientifically valid research. Double-blind, placebo-controlled studies are preferable, but compassionate use reports and expert review articles are used in a thorough review of the literature conducted through Medline with the National Library of Medicine. When only data that will not withstand objective scrutiny are available, a recommendation is identified as a consensus of experts. Guidelines are applicable to all physicians who address the subject without regard to specialty training or interests and are intended to indicate the preferable, but not necessarily the only, acceptable approach to a specific problem. Guidelines are intended to be flexible and must be distinguished from standards of care, which are inflexible and rarely violated. Given the wide range of specifics in any health care problem, the physician must always choose the course best suited to the individual patient and the variables in existence at the moment of decision.

Guidelines are developed under the auspices of the American College of Gastroenterology and its Practice Parameters Committee and approved by the Board of Trustees. Each has been intensely reviewed and revised by the Committee, other experts in the field, physicians who will use them, and specialists in the science of decision analysis. The recommendations of each guideline are therefore considered valid at the time of their production based on the data available. New developments in medical research and practice pertinent to each guideline will be reviewed at a time established and indicated at publication to assure continued validity.

* J. Patrick Waring, M.D., Atlanta, GA; James L. Alchord, M.D., Jackson, MS; Todd H. Baron, M.D., Birmingham, AL; Eugene M. Bozymski, M.D., Chapel Hill, NC; Patrick G. Brady, M.D., Tampa, FL; W. Scott Brooks, Jr., M.D., Atlanta, GA; William D. Carey, M.D., Cleveland, OH; Kenneth R. DeVault, M.D., Jacksonville, FL; Norman D. Grace, M.D., Boston, MA; John I. Hughes, M.D., Houston, TX; Simon K. Lo, M.D., Torrance, CA; Jack A. DiPalma, M.D., Schenectady, NY; George W. Meyer, M.D., Atlanta, GA; John F. Reinus, M.D., Bronx, NY; Marvin M. Schuster, M.D., Baltimore, MD; Douglas M. Simon, M.D., New Rochelle, NY; Robert H. Squires, Jr., M.D., Dallas, TX; Rosalind U. Van Stolk, M.D., Cleveland, OH; John Wo, M.D., Atlanta, GA; and Gregory Zuccaro, Jr., M.D., Cleveland, OH.

Received June 24, 1998; accepted Aug. 12, 1998.

\section{INTRODUCTION}

The relationship between nonsteroidal anti-inflammatory drugs (NSAIDs) and gastroduodenal injury is now well established (1,2). Patients with rheumatoid arthritis (RA) and osteoarthritis (OA) taking NSAIDs have an ulcer incidence of approximately 15-20\% (3, 4). Complications of ulcer disease, i.e., hemorrhage and perforation, occur far more often in patients taking these agents than in comparable control groups (5-7). The overall risk for serious adverse gastrointestinal (GI) events in patients taking NSAIDs is about three times greater than that of controls. In elderly patients $(>60 \mathrm{yr})$, this risk rises to more than five times that of controls, whereas the risk for younger patients is only slightly more than one-and-one-half times (6). In elderly patients taking NSAIDs the relative risk of GI surgery is ten times, and for GI cause of death, about fourand-one-half times greater than in control groups (6). Approximately 20 million patients in the US take NSAIDs on a regular basis; the risk for hospitalization for serious GI adverse effects is $1-2 \%$, resulting in approximately 200,000 to 400,000 hospitalizations per year at an average cost of $\$ 4,000$ per patient, or $0.8-1.6$ billion dollars annually $(8,9)$. The economic impact of this problem is increased by multiple other factors, including lost wages, postop care, etc.

Two major issues confront clinicians using these agents: 1) the prevention of NSAID-induced ulcers, especially in high risk groups, and 2) their treatment, often when underlying disease mandates continued NSAID use. A third problem is the recent recognition of small bowel and colon NSAID-related mucosal injury. The purpose of this guideline is to make recommendations based on the pertinent medical literature addressing these problems.

\section{PREVENTION OF NSAID-INDUCED ULCERS}

\section{Recommendation}

Patients at high risk for hemorrhage and perforation from aspirin and other NSAID-induced ulcers should be considered for prophylaxis with misoprostol. Proton pump inhibitors are an acceptable alternative for prevention of NSAID-related complications. $\mathrm{H} 2$ receptor antagonists have been shown to prevent only duodenal ulcer, and there- 
TABLE 1

Factors Related to Increased Risk of NSAID Induced GI Complications

\begin{tabular}{lccc}
\hline \multicolumn{1}{c}{ Risk Factor } & Relative Risk & $95 \%$ CI & Ref \# \\
\hline Overall & 2.74 & $2.54-2.97$ & 6 \\
Age $(>60)$ & 5.52 & $4.63-6.60$ & 6 \\
Prior GI event & 4.76 & $4.05-5.59$ & 6 \\
High dosage $(>2 \times$ & 10.1 & $4.6-22.0$ & 43 \\
$\quad$ normal) & & & \\
Concurrent corticosteroids & 4.4 & $2.0-9.7$ & 44 \\
Concurrent anticoagulants & 12.7 & $6.3-25.7$ & 45 \\
\hline
\end{tabular}

fore cannot be recommended for prophylaxis. Factors that have been identified as placing patients at increased risk for NSAID-related GI complications include the following:

1. Prior history of gastrointestinal event (ulcer, hemorrhage)

2. Age $>60 y r$

\section{High dosage}

\section{Concurrent use of corticosteroids}

\section{Concurrent use of anticoagulants}

Although a direct link has not been established between NSAID-induced ulcers and gastrointestinal hemorrhage and perforation, these complications occur significantly more often in patients taking NSAIDs when compared with control groups. As noted above, these serious adverse events also tend to occur more often in high risk groups which include patients with a prior history of a GI event, advanced age ( $>60 \mathrm{yr})$, high NSAID dosage, and concomitant use of corticosteroids or anticoagulants (Table 1). Several randomized controlled trials (RCTs) have been published attempting to show that various therapeutic maneuvers can prevent the development of gastric ulcer (GU) and duodenal ulcer (DU) in patients taking NSAIDs. However, only one study has been published linking any cotherapy with prevention of the complications of ulcer disease, i.e., bleeding and perforation (10). It is not unreasonable, however, to assume that prevention of NSAID-induced ulcer should be associated with a similar prevention of the complications of ulcer disease.

Numerous RCTs have been carried out, both in normal volunteers and in patients with arthritic disorders, to evaluate the efficacy of coadministration of various agents for the prevention of both NSAID-related, nonulcer gastropathy and GU and DU (11-28). Generally, these have shown that concomitant administration of the prostaglandin E1 analog misoprostol along with various NSAIDs can prevent both GU and DU (11-23); that the proton pump inhibitor (PPI) (24-26) omeprazole reduces GU and prevents DU; and that $\mathrm{H} 2$ receptor antagonists are effective in preventing DU but not GU $(27,28)$.

Prophylaxis with prostaglandins or PPIs for all patients taking NSAIDs is unnecessary and cost-prohibitive. Studies with misoprostol have shown that in high risk groups, prophylaxis may be cost-effective (7). The numerous factors involved in these analyses, i.e., the time lost from work, expense of hospitalization with or without surgery, varying costs of prophylactic and therapeutic drugs, and quality of life issues make it very difficult to determine the cost effectiveness of prophylactic therapy for NSAID-related ulcer disease and its complications.

\section{Risk Factors}

All patients taking NSAIDs do not require prophylaxis. These drugs are used extensively as treatment for limited illnesses. Anti-inflammatory doses of numerous NSAIDs have been administered for short periods of time (up to 7 days) to large numbers of young, healthy volunteers without any reports of significant GI bleeding or other serious event (29). Many patients of all ages, however, take anti-inflammatory NSAID doses for longer periods, and many casecontrol studies have shown that, in these patients, significant GI bleeding and other severe adverse events occur more commonly than in matched control patients (30-37). An increased risk of GI bleeding has even been noted in patients taking low dose aspirin therapy for cardiovascular prophylaxis (38-41). Obviously, as all patients taking NSAIDs do not develop serious complications, risk factors must exist in some patients that increase the incidence of GI bleeding, perforation, surgery, and even death.

A series of nested case-controlled studies based on hospitalization for GI hemorrhage of Medicaid recipients aged $>65 \mathrm{yr}$ in the state of Tennessee showed an increased bleeding risk for patients $>65 \mathrm{yr}$ (odds ratio 4.7), increased dose (odds ratio 8.0), concomitant corticosteroid (odds ratio 4.4 ), or anticoagulant therapy (odds ratio 12.7), and short term onset of use ( $<1$ month) (7.2) (42-45). A large autopsy series on patients with a history of NSAID use showed that gastric and duodenal lesions were more common in patients who took NSAIDs for $<3$ months, whereas patients with a longer duration of therapy tended to have more lesions in the small bowel and colon (46).

A large retrospective cohort study, also based on data from Medicaid patients, confirmed the overall increased risk for GI bleeding in patients taking NSAIDs, especially over the aged $>60 \mathrm{yr}$ (47). Similar data have been obtained from other large cohort studies $(40,48,49)$. In a large prospective, multicenter study in patients with RA $(\mathrm{N}=2747)$ and OA $(\mathrm{N}=1091)$, the principal risk factors for hospitalization for serious GI events were age, prior NSAID GI side effect, prior GI hospitalization, corticosteroid use, and debility expressed as a level of disability. The overall risk in this study for hospitalization during NSAID therapy in patients with RA was $1.58 \%$ (5).

A large meta-analysis of these and other studies showed an overall odds ratio for GI bleeding of 2.74 in all patients taking NSAIDs. Patients with a prior gastrointestinal event had an odds ratio of 4.76. Age ( $>60 \mathrm{yr}$ ), concurrent corticosteroids, and shorter duration ( $>3$ months) of NSAID 
TABLE 2

NSAID Protection Studies With Misoprostol for Gastric Ulcer

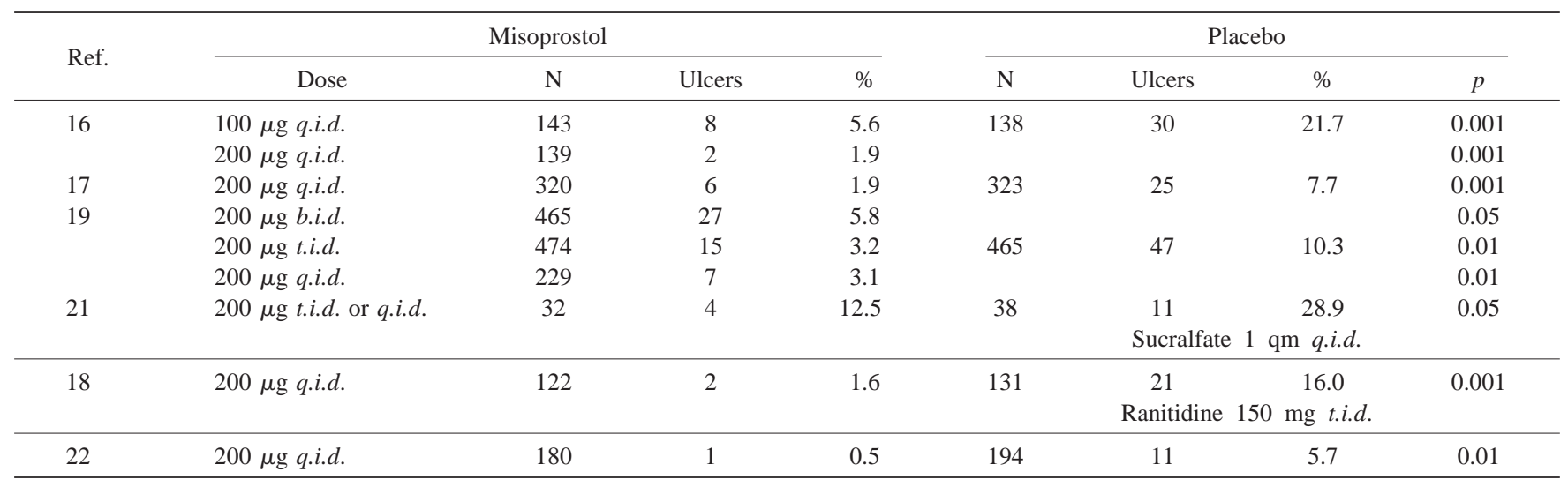

consumption were all associated with an increased relative risk ratio for serious adverse GI events (Table 1). Gender, smoking, and alcohol were not found to be independent risk factors (6).

A large, double blind, randomized, controlled treatment prevention trial in $>8000$ patients with RA also identified a history of cardiovascular disease as a risk factor for UGI complications of NSAID use (odds ratio 1.84). In this same trial, age $>75$ yr (odds ratio 2.48), prior peptic ulcer (odds ratio 2.29), and prior GI bleeding (odds ratio 2.56) were again associated with increased risk (10).

There appears to be some difference between the various NSAIDs with reference to the incidence of significant GI bleeding and other adverse events. Four large cohort studies have been published comparing the risk of these complications associated with the various NSAIDs. Overall, these studies show an increased toxicity for ketorolac and piroxicam, and intermediate toxicity for naproxen, indomethacin, ketoprofen, and diclofenac. Ibuprofen in all studies was less toxic than the other agents, but this is probably related to the generally lower doses employed with this agent, which is available over the counter (50-54).

No good prospective controlled data for GI bleeding and other ulcer complications is available for the recently introduced, newer NSAIDs purported to be less toxic to the upper GI mucosa (nabumetone, etodolac, oxaproxin). Several large postmarketing, open label studies involving thousands of patients in Europe suggest that bleeding rates with these agents are in the range of $0.5 \%$ (55-59). These studies have recently been reviewed in the American literature (60). Of these agents, nabumetone has been the most extensively studied. A 12-wk endoscopic study compared nabumetone (1000 mg q.d.), ibuprofen (600 mg q.i.d), and the same dose of ibuprofen plus misoprostol in 171 patients with OA. There was no difference in the number of ulcers found in the nabumetone and nabumetone/misoprostol groups (one and zero, respectively), which were significantly less $(p<0.01)$ than the eight ulcers found in the ibuprofen group (61). Another endoscopic study compared nabumetone $1000 \mathrm{mg}$ q.d. with naproxen $500 \mathrm{mg}$ b.i.d. in RA patients for $4 \mathrm{wk}$. One ulcer was found in the 22 patients taking nabumetone and eight in the 30 patients treated with naproxen $(p=0.01)$ (62). In a third study, 27 patients with either RA or OA were followed for $5 \mathrm{yr}$ taking either naproxen $250 \mathrm{mg}$ b.i.d. or nabumetone $1000 \mathrm{mg}$ q.d. Ulcers were found in eight of 12 patients taking naproxen and in one of 15 taking nabumetone $(p=0.02)$. No bleeding was found in either group (63).

The combination of advanced age with any of the other noted risk factors has also been noted to further increase the probability of ulcer complications in NSAID users, especially in the first month of therapy. The relative risk of requiring GI surgery or GI cause of death increases dramatically in patients $>60 \mathrm{yr}(6)$. Although a $15-25 \%$ incidence of gastric and/or duodenal ulcer has been demonstrated in all patients taking NSAIDs $(3,4)$, the bleeding rate is estimated by most experts at only $2-4 \%$. In a meta-analysis of 100 trials of NSAID therapy, bleeding occurred in 24 of 1157 patients taking active drug (2\%), compared with only eight of 1103 taking placebo $(0.6 \%)$ (64). It can be derived from these data that about only one in 10 NSAID-induced ulcer bleeds. A recent large, multicenter, double-blind RCT in $>800$ arthritic patients taking NSAIDs showed that the incidence of perforation, outlet obstruction, and hemorrhage was reduced by $40 \%$ in those subjects taking misoprostol compared with placebo. In this study, these complications were seen in 22 of 4404 patients on misoprostol compared with 42 of 4439 taking placebo $(p=0.049)(10)$.

\section{Prostaglandins}

Currently, the only available prostaglandin is misoprostol, a synthetic prostaglandin E1 analog. A series of RCTs in normal volunteers have shown that this agent can prevent acute NSAID-related erosion and ulceration (11-15). Subsequent RCTs in patients with OA and RA have demonstrated that misoprostol was significantly better than placebo, sucralfate, and ranitidine for the prevention of NSAID-related GU (Table 2). Misoprostol was also signif- 
TABLE 3

NSAID Protection Studies With Misoprostol for Duodenal Ulcer

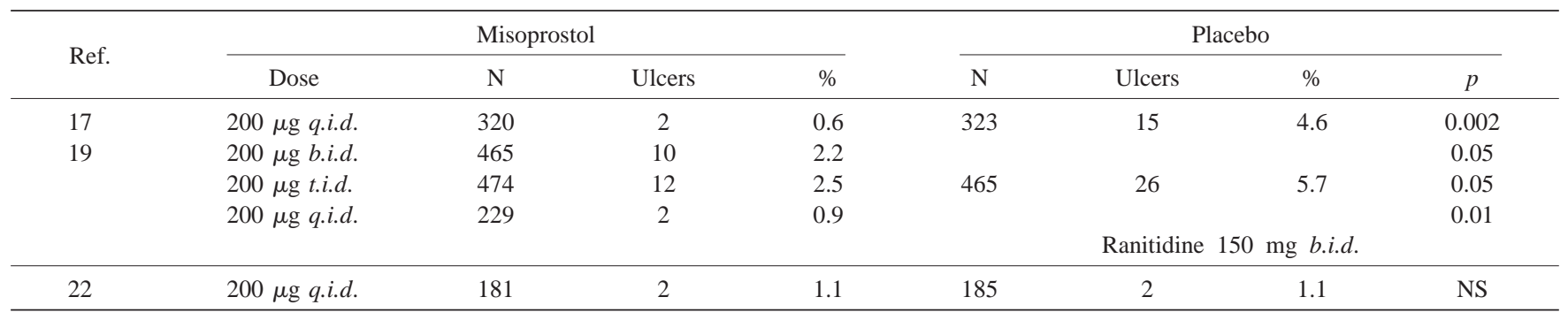

TABLE 4

NSAID Protection Studies With Omeprazole

\begin{tabular}{|c|c|c|c|c|}
\hline \multirow{2}{*}{ Ref. } & \multirow{2}{*}{ Regimen } & \multicolumn{3}{|c|}{ Ulcers $(\%)$} \\
\hline & & GU & DU & $p^{*}$ \\
\hline 24 & O 20 q.d. & 2/85 (2.4) & $2 / 85(2.4)$ & $>0.005 \mathrm{vs}$ placebo \\
\hline \multirow[t]{2}{*}{25} & O 20 q.d. & $35 / 274(12.0)$ & 7/274 (3) & O .001 vs $\mathrm{M}$ and placebo \\
\hline & M 200 b.i.d. & $31 / 296(9.5)$ & $30 / 296(10)$ & \\
\hline 26 & R 150 b.i.d. & $35 / 215(16.3)$ & $7 / 215(4.2)$ & $2 / 215(0.9)$ \\
\hline
\end{tabular}

* All ulcers combined (GU and DU).

$\mathrm{O}=$ omeprazole (in $\mathrm{mg}$ ); $\mathrm{M}=$ misoprostol (in $\mu \mathrm{g}$ ); $\mathrm{R}=$ ranitidine (in $\mathrm{mg}$ ).

icantly better than placebo for the prevention of duodenal ulcer. Ranitidine and misoprostol were equally effective in preventing DU (Table 3). Lower doses of misoprostol were also effective in preventing GU and DU with a side effect profile indistinguishable from that of placebo $(16-19,21$, 22). In another double blind RCT, two groups of arthritic patients requiring chronic NSAID therapy with either endoscopically normal $(\mathrm{N}=223)$ or nonulcer-injured gastroduodenal mucosa $(\mathrm{N}=778)$ were treated with NSAIDs for 2 wk with concurrently administered misoprostol (400-800 $\mu \mathrm{g} /$ day) or placebo. The incidence of severe mucosal damage, including ulcer, was significantly reduced by misoprostol in the previously endoscopically normal subjects and also in the group with preexisting nonulcer damage $(p<$ 0.001) (20). A recent large meta-analysis of RCTs of prevention of NSAID-induced gastric mucosal injury by misoprostol or $\mathrm{H} 2$ receptor antagonists, published between 1970 and 1994, showed that misoprostol (but not $\mathrm{H} 2$ receptor antagonists) was beneficial in the prevention of NSAIDinduced GUs. It was also found that the number of patients to be treated to prevent one GU with short and long term NSAID therapy is 11 and 15 , respectively (23).

\section{Proton pump inhibitors}

Omeprazole, the most extensively studied PPI, has a protective effect against NSAID-related mucosal injury. Not unexpectedly, because of its potent acid-inhibiting property, it prevents DU in patients taking NSAIDs. There is evidence that omeprazole also protects against GU. In a crossover, double-blind RCT, 20 normal volunteers were given aspirin $650 \mathrm{mg}$ q.i.d. with either placebo or omeprazole $40 \mathrm{mg} /$ day for 14 days, with endoscopy before and after each treatment period. Omeprazole significantly decreased aspirin-induced gastric mucosal injury $(p<0.01)$ by protecting $85 \%$ of the subjects from extensive erosions or ulcer, whereas $70 \%$ of the subjects developed severe injury (rate 3 or 4 on $0-4$ scale) on aspirin and placebo. No duodenal injury was seen in any grade or any subject on omeprazole, whereas $50 \%$ on placebo developed erosions and 15\% had DU $(p<0.001)$ (65).

Three large RCTs have been carried out in patients with OA and RA comparing omeprazole with placebo, misoprostol, and ranitidine for the prevention of GU and DU (Table 4) (24-26). Overall, omeprazole significantly reduced the total number of NSAID-related ulcers when compared with placebo and ranitidine (26). It was more effective than misoprostol in preventing DU, and equally so in reducing GU (25). It should be noted that the lowest effective dose of misoprostol was used in this study, and that most of the overall prevention in NSAID-related ulcer in the placebocontrolled studies was due to a reduction in the numbers of duodenal ulcers.

\section{H2 receptor antagonists}

Although commonly coadministered with NSAIDs, H2 receptor antagonists (H2RAs) have not been shown to prevent gastric ulcer, the most common NSAID-related lesion, but do prevent DU. Ranitidine has been the most extensively 
studied H2RA. In two large, multicenter RCTs, ranitidine (150 mg, b.i.d.) or matching placebo was given to patients with OA and RA in conjunction with various NSAIDs. In both studies there was no difference in the occurrence of gastric ulcer between the two groups; however, the incidence of duodenal ulcer was significantly reduced in both studies in the ranitidine group $(27,28)$. Nizatidine $(150 \mathrm{mg}$ b.i.d.), in an RCT of 496 patients with OA, did not lower the overall incidence of NSAID-related ulcers. However, a separate analysis of high risk groups (patients with ulcer history and patients $>65 \mathrm{yr}$ of age) showed statistically less GU and DU in patients receiving nizatidine $(p=0.035$ and $p=$ 0.042 , respectively) (66). In a nonplacebo-controlled RCT of 221 arthritic patients with recently healed NSAID-related ulcers, cumulative relapse rates for nizatidine $150 \mathrm{mg}$ HS and $150 \mathrm{mg}$ b.i.d. were $5.5 \%$ and $1.8 \%$, respectively (67). A double-blind RCT of famotidine for the prevention of gastric and duodenal ulcers caused by NSAIDs was performed in arthritic patients receiving placebo, famotidine $20 \mathrm{mg}$ b.i.d., and famotidine $40 \mathrm{mg}$ b.i.d., concurrently with the usual NSAID. The cumulative incidence of GU was $20 \%$ in the placebo group $(\mathrm{n}=93), 13 \%$ in the patients receiving famotidine $20 \mathrm{mg}$ b.i.d., (NS), and $8 \%$ in the group receiving famotidine $40 \mathrm{mg}$ b.i.d., ( $p=0.03 \mathrm{vs}$ placebo) (68). This study, however, has been criticized because of the small minimum ulcer size of $0.3 \mathrm{~cm}$. In a similar study from the same group of investigators, patients with RA or OA with $\mathrm{GU}$ or DU were treated with famotidine $40 \mathrm{mg}$ b.i.d. The subjects with healed ulcers were then randomized to 6 months of therapy with famotidine $40 \mathrm{mg}$ b.i.d. or placebo. Ulcer recurrence was seen in $26 \%$ of the subjects on famotidine, compared with $54 \%$ with placebo $(p=0.01)$. Despite the superiority over placebo, the recurrence rate of ulcer in patients on famotidine was unacceptably high (69). High dose ranitidine (300 $\mathrm{mg}$ b.i.d.) was found to be ineffective for the prevention of gastric ulcers, but was protective against duodenal ulcer. Patients with rheumatoid arthritis and a past history of peptic ulcer disease were followed for $1 \mathrm{yr}$ on NSAIDs with either high dose (300 mg b.i.d.) ranitidine $(n=10)$ or placebo $(n=10)$. Four patients in the placebo group had recurrent DU and none in the ranitidine group $(p=0.04)$. Six recurrent GUs were found in the placebo group and three in the ranitidine group $(p=0.18)$ (70). Recurrence of DU in patients taking NSAIDs is more likely when there is a past history of that disease.

\section{Other agents}

Sucralfate has not been shown to be effective in preventing NSAID-related ulcers $(13,18,71)$. In a recent study from two sites in Europe, 107 arthritic patients were randomly allocated to receive diclofenac $200 \mathrm{mg}$ /day or naproxen $1 \mathrm{~g} /$ day, plus sucralfate gel $1 \mathrm{~g}$ b.i.d. $(\mathrm{n}=53)$ or identical placebo $(\mathrm{n}=54)$ for 14 days in an RCT. Although there was an unexplained difference in the incidence of ulcer between the two centers, there was an overall decrease in the occurrence of ulcer between patients receiving sucralfate
(8\%) compared with placebo $(28 \%)(p<0.05)$. Both GU and DU were analyzed together in this study, and the proven efficacy of sucralfate for DU may account for these results (72). Studies have shown that antacids and buffered tablets do not protect against NSAID injury (73-75). Enteric coating may be helpful in reducing aspirin-related gastric and duodenal ulcer $(74,75)$, but does not reduce the risk of NSAID-related ulcer complications (76).

Several new compounds have shown promise in both animal studies and patients. In a double-blind RCT, sulglycotide $200 \mathrm{mg}$ t.i.d. or placebo was coadministered with an NSAID to patients with rheumatoid arthritis. Gastric or duodenal ulcer was seen in six of $42(18 \%)$ in the sulglycotide group and in 15 of $44(34 \%)$ in the placebo group $(p=0.02)(77)$. Another new agent under study is zinc acexonite (ZAC). Either ZAC $300 \mathrm{mg}$ /day or placebo was randomly assigned in a double blind manner to 276 arthritic patients receiving NSAIDs. Of 141 patients receiving ZAC, no GU and only one DU (0.9\%) was found, whereas 12 of 135 subjects $(6.0 \%)$ on placebo developed an ulcer. Unfortunately, this study suffers from a high withdrawal and loss to follow up rate (67/276) (78). Because of lack of confirmatory studies, no recommendations can be made at this time concerning either of these agents.

More promising is the development of new, purportedly nontoxic, NSAIDs. These fall into two groups: COX-2selective inhibitors, and nitric oxide (NO)-releasing NSAIDs. Studies of these agents are very limited. Meloxicam (15 mg/day), a weak COX-2 inhibitor (COX 1: COX-2 ratio 0.33 ), has been studied in an uncontrolled manner in 357 patients with rheumatoid arthritis. Severe side effects (bleeding, perforation, and ulcer) were seen in only three patients $(0.8 \%)$ (79). The GI effects of more potent COX-2 inhibitors have thus far only been studied in normal volunteers. These studies have shown a lesser degree of overall erosive injury and ulcer when compared with other NSAIDs $(80,81)$. At this time, there are no published RCTs of NO-NSAIDs in patients or human volunteers.

\section{TREATMENT OF NSAID-INDUCED ULCERS}

\section{Recommendation}

NSAID-induced ulcer disease may be treated with any approved therapy for ulcer disease. It is preferable to stop NSAID therapy when ulcer disease occurs. A proton pump inhibitor is the agent of choice when NSAIDs must be continued in the presence of ulcer disease and for large ulcers. Treatment for $\mathrm{H}$. pylori is recommended for patients taking NSAIDs who have ulcers and are infected with this organism.

NSAID-related ulcers may be treated effectively with any approved therapy for peptic ulcer disease. Healing generally is more rapid when the NSAID is discontinued and compares favorably with healing rates for peptic ulcer disease not associated with NSAID intake. Several recent RCTs provide what are probably the best data on the healing rates 
TABLE 5

Treatment of NSAID-Related Ulcers

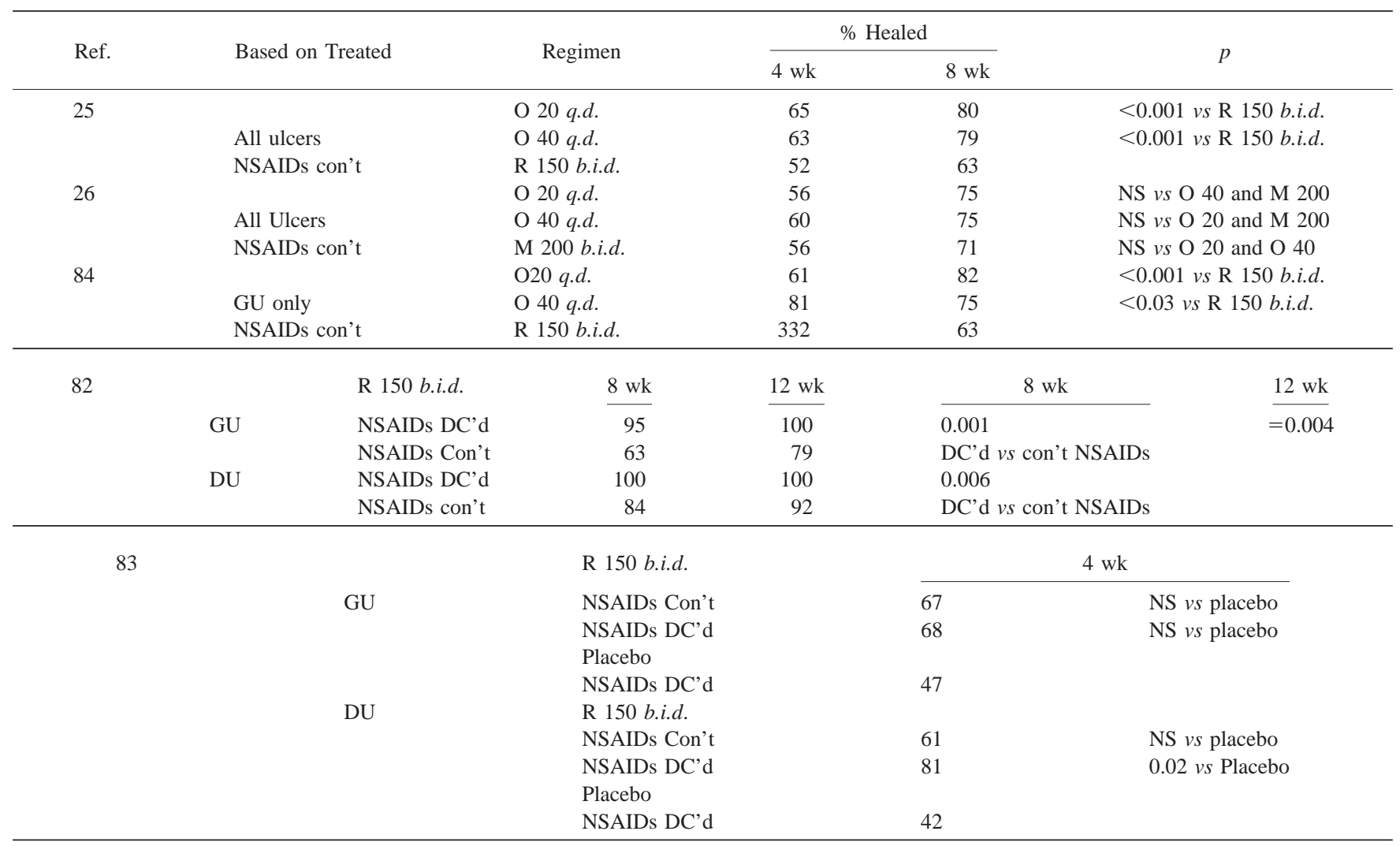

$\mathrm{O}=$ omeprazole (in $\mathrm{mg}$ ); $\mathrm{M}=$ misoprostol (in $\mu \mathrm{g}$ ); $\mathrm{R}=$ ranitidine (in $\mathrm{mg}$ ).

of NSAID-related ulcers treated with H2 RAs or PPI's (Table 5). These studies showed that good healing rates could be obtained at both 4 and 8 wk with all of the agents employed. Generally, healing rates were better for all treatments when NSAIDs were discontinued, but satisfactory healing still occurred with prolonged therapy when it was necessary to continue NSAID treatment. Healing rates in patients taking omeprazole were significantly better than those in patients taking ranitidine when NSAIDs were continued $(25,26,82-84)$. In an uncontrolled study, famotidine $40 \mathrm{mg}$ /day was given to 71 patients with endoscopicallyproven GU for $8 \mathrm{wk}$. The healing rate for patients with NSAID-related ulcers was compared with that for idiopathic ulcer. It was found that healing occurred in 46 of 48 (96\%) of patients with NSAID-related ulcer, which was significantly greater than the 17 of $23(74 \%)$ seen for idiopathic ulcer $(p=0.01)(85)$. In a nonplacebo-controlled study, three doses of nizatidine (150 mg HS, $150 \mathrm{mg}$ b.i.d., $300 \mathrm{mg}$ b.i.d.) were given to patients with active GU or DU while they continued their original NSAID. After 8 wk of therapy, $>90 \%$ of the ulcers of all three groups were healed. There was a tendency to higher healing rates for GU after four weeks in the high dose (300 mg b.i.d.) nizatidine group (67).

In another RCT, substitution of enteric-coated aspirin in patients with ASA-related ulcers did not increase healing rates in patients treated with cimetidine $(400 \mathrm{mg} /$ day $)$ and antacids and, in fact, seven patients given enteric-coated aspirin failed to heal their ulcers, whereas 15 of 16 healed after aspirin was discontinued in all forms (86).

Helicobacter pylori infection has been strongly associated with peptic ulcer disease, especially duodenal ulcer. However, this association has not been demonstrated in patients with NSAID-related ulcer (87-90). In one study, however, gastropathy was more severe in $\mathrm{H}$. pylori-positive patients (88). Some recent studies have shown that the incidence of DU is increased in $\mathrm{H}$. pylori-positive patients taking NSAIDs $(91,92)$. However, in another study $H$. pylori eradication did not increase the healing of GU and DU associated with long-term NSAID use (93). It has been recently reported that eradication of $\mathrm{H}$. pylori before NSAID therapy strikingly reduces the incidence of ulcer disease in patients being treated with naproxen $(750 \mathrm{mg} /$ day $)$. Standard triple therapy (bismuth subcitrate $120 \mathrm{mg}$ q.i.d., tetracycline $500 \mathrm{mg}$ q.i.d., and metronidazole $400 \mathrm{mg}$ q.i.d) was given to $45 \mathrm{H}$. pylori-positive patients before $8 \mathrm{wk}$ of naproxen therapy. Naproxen alone was given to 47 patients over the same period. In the triple therapy group, only three patients (7\%) developed ulcer, two of whom were found to have failed $H$. pylori eradication. In the naproxen group, 12 patients (26\%) had ulcers, one of which bled (94). Another recent case-control study of ulcer bleeding in 487 elderly patients revealed that NSAID usage (odds ratio 4.93) and $H$. 
pylori status (odds ratio 2.80) increased risk substantially, but there was no evidence of interaction (95). In view of the conflicting data, screening for $\mathrm{H}$. pylori infection cannot be recommended for all patients receiving NSAIDs. There is some recent evidence that $H$. pylori-negative patients heal more slowly than those who are positive for this organism (26). However, experts still agree that $H$. pylori-positive patients with a past or current history of ulcer requiring NSAID therapy should be treated for the infection, as it cannot be determined whether the prior ulcer was due to NSAID therapy or to $H$. pylori infection.

\section{NSAID INJURY TO THE SMALL BOWEL AND COLON}

\section{Recommendations}

NSAID-related injury to both the small and large bowel has includes occult and frank bleeding, perforation, obstruction, an acute colitis, and exacerbation of existing colon disease. Physicians prescribing NSAIDs should be aware of these potential complications.

NSAID-related injury to the small bowel and colon has only recently been described and has been documented primarily by anecdotal case reports. However, these are numerous and constitute a significant body of literature. The overall incidence of NSAID-related injury to the gastrointestinal tract distal to the duodenum is much less than that seen in the stomach and proximal duodenum. Nevertheless, it occurs frequently enough to warrant serious consideration by physicians treating patients with NSAIDs.

\section{Small bowel injury}

Injury to the small intestine can be manifested by perforation, ulceration and stricture, or by an NSAID-induced enteropathy $(31,46,96-98)$. Perforation of the small bowel, although a rare complication of NSAID use, was found in one retrospective review to be significantly more common among patients taking NSAIDs when compared with controls (31). More commonly seen are small intestinal ulcers and strictures (95). Diaphragm-like strictures, often with a very small lumen, are highly characteristic of NSAID injury to the small bowel. Broader-based strictures, often associated with intestinal ulceration, have also been reported. These lesions are commonly associated with obstructivelike symptoms. In a retrospective review of all small bowel resections over an $11 \mathrm{yr}$ period, seven of 456 resections were thought to be related to NSAID injury (97). A more recently reported prospective autopsy series looked at the small bowel of 713 consecutive patients. Seventy-four of these patients had taken NSAIDs on a regular basis, and 249 had ingested them to some degree during the preceding 6 months. Small intestinal ulceration, unrelated to any known pathologic condition, i.e., Crohn's disease, etc., were found in 21 subjects who had taken NSAIDs, which was significantly greater than those patients who were non-NSAID users (46). These small intestinal lesions are extremely difficult to diagnose. Careful small bowel x-rays or small bowel enemas may be necessary, especially in the case of the diaphragm-like lesions that often resemble the normally occurring plica circularis. Small bowel enteroscopy is now being used more regularly and may well be necessary to diagnose some of these lesions $(99,100)$.

Small intestinal micro bleeding, protein loss and malabsorption have been attributed to an NSAID-related enteropathy (101). Studies using 51Cr-EDTA have shown both in normal volunteers and patients that intestinal permeability was markedly increased in patients shortly after treatment with NSAIDs $(102,103)$. Studies in rats suggests that the enterohepatic recirculation of NSAIDs is critical to this effect (104). Increased small intestinal inflammation has also been demonstrated using 111 indium-labeled neutrophils $(105,106)$. Using scintigraphic techniques, it has been shown that $\geq 50 \%$ of patients who are on NSAIDs more than 6 months develop abnormalities (105). Unlike inflammatory bowel disease, in which scintigraphic abnormalities are seen on early scans, findings in patients on NSAIDs are noted later (at about $20 \mathrm{~h}$ ) (106). The relationship in patients taking NSAIDs between increased intestinal permeability, which occurs quite early, and inflammation, which occurs later, is as yet unknown, but is felt to be a part of the evolving complex of small bowel injury due to NSAID ingestion (101). There is no evidence that prostaglandins or any other therapeutic agent prevents or reduces NSAID injury to the small bowel.

\section{Injury to the colon}

Injury to the lower gastrointestinal tract can be divided into two types: that which affects a previously normal colon, and that which aggravates preexisting disease. An acute colitis occurring in a previously normal colon of patients taking NSAIDs has been reported. A disproportionately high number of these cases are associated with the fenemate group of NSAIDs (meclofenamate and mefenamic acid). The majority of these data are based on various case reports, and these are summarized in a recent extensive review (107). This "colitis" mimics inflammatory bowel disease and presents most commonly as a bloody diarrhea. The disease remits upon discontinuance of the offending NSAID. Diagnosis is made by endoscopic biopsy, which usually rules out classic inflammatory bowel disease and is reported as showing "nonspecific inflammatory changes". Another entity that is often reported in these patients is that of collagenous colitis. In one review of 30 patients with that disease, 19 were found to have been on NSAID therapy (108). Nevertheless, this type of colitis is a rare complication of NSAID therapy, with $<50$ cases being reported in the medical literature (101). In one series of $>250$ patients on NSAID therapy for RA and OA, no cases of colonic inflammation were found (109). Solitary ulceration has been reported in the cecum and transverse and sigmoid colons in patients taking NSAIDs $(110,112)$. In one large, retrospective, case-controlled study reviewing large and small intes- 
tinal perforation and hemorrhage, one in four patients presenting in this manner had a history of NSAID ingestion that was twice that seen with normal controls (31). Proctitis and rectal bleeding $(113,114)$, as well as ulceration of the rectum (115), is more commonly associated with the use of suppositories, usually indomethacin or aspirin (114). Stricture of the rectum has also been reported (106). Biopsies differentiate this lesion from Crohn's disease. The incidence of these lesions has not been determined, especially in the United States where the use of NSAID suppositories is rare.

NSAID-related complications have been reported in patients with pre-existing diverticulosis $(116,117)$ and inflammatory bowel disease $(119,120)$. In a controlled prospective study evaluating both complications of diverticulosis and perforation, it was found that 31 of 92 patients with complicated diverticular disease were taking NSAIDs, and this was significantly greater than the age-matched control group. Nineteen of 31 patients taking NSAIDs had presented with perforation, whereas only 8 of 61 patients were non-NSAID users $(p<0.001)$ (116). Another case-controlled study of patients with severe complications of diverticulosis showed that $48 \%$ of these patients were taking NSAIDs when compared with matched controls $(p<0.01)$ (117). More recently, in a retrospective review of 13 patients with unequivocal stigmata of recent diverticular hemorrhage, $12(92 \%)$ were found to have been recently exposed to NSAIDs and/or aspirin (118).

There are some data to indicate that NSAIDs may have a detrimental effect on patients with inflammatory bowel disease and in patients previously in remission, inducing a relapse only a few days after starting NSAIDs $(119,120)$. A recent case-control study of 200 hospital admissions for acute inflammatory bowel disease showed that the overall odds ratios for current and recent exposure to NSAIDs were 1.77 and 1.93, respectively, when compared with 1198 community controls (121).

There are no data to support any type of prophylactic therapy directed at the prevention of NSAID-related injury to the colon.

Reprint requests and correspondence: Frank L. Lanza, M.D., 2500 Fondren, Suite 250, Houston, TX 77063.

\section{REFERENCES}

1. Cryer B, Feldman M. Effects of nonsteroidal anti-inflammatory drugs on endogenous gastrointestinal prostaglandins and therapeutic strategies for prevention and treatment of non-steroidal, anti-inflammatory drug-induced damage. Arch Intern Med 1992;152:1145-55.

2. Soll AH. Moderator: Nonsteroidal anti-inflammatory drugs and peptic ulcer disease. Ann Intern Med 1991;114:307-19.

3. Larkai EN, Smith JL, Lidsky MD, et al. Gastroduodenal mucosa and dyspeptic symptoms in arthritic patients during chronic nonsteroidal anti-inflammatory drug use. Am J Gastronenterol 1987:1153-8.

4. Bellary SV, Isaacs PET, Lee FI. Upper gastrointestinal lesions in elderly patients presenting for endoscopy; relevance of NSAID usage. Am J Gastroenterol 1991;86:961-4.

5. Fries JF, Williams CA, Bloch DA, et al. Nonsteroidal anti-inflammatory drug-associated gastropathy: Incidence and risk factor models. Am J Med 1991;91:213-22.
6. Gabriel SE, Jaakkimainen L, Bombardier C. Risk for serious gastrointestinal complications related to use of nonsteroidal anti-inflammatory drugs. A meta-analysis. Ann Intern Med 1991;115:787-96.

7. Lanas A, Serrano P, Bajador E, et al. Evidence of aspirin use in both upper and lower gastrointestinal perforation. Gastroenterology 1997; 112:683-9.

8. Smalley WE, Griffin MR. The risks and costs of upper gastrointestinal disease attributable to NSAIDs. Gastroenterol Clin North Am 1996;25:373-96.

9. Smalley WE, Griffin MR, Fought RL, et al. Excess costs from gastrointestinal disease associated with nonsteroidal anti-inflammatory drugs. J Gen Intern Med 1996;11:461-9.

10. Silverstein FE, Graham DY, Senior JR, et al. 8Misoprostol reduces serious gastrointestinal complications in patients with rheumatoid arthritis receiving nonsteroidal anti-inflammatory drugs: A randomized, double-blind, placebo-controlled trial. Ann Intern Med 1995; 123:241-9.

11. Lanza FL. Double-blind study of prophylactic effect of misoprostol on lesions of gastric and duodenal mucosa induced by oral administration of tolmetin in healthy subjects. Dig Dis Sci 1986;31:131-6.

12. Aadland E, Fausa O, Vatn M, et al. Protection by misoprostol against naproxen-induced gastric mucosal damage. Am J Med 1987;83:3740.

13. Lanza RL, Peace K, Gustitus L, et al. A blinded endoscopic comparative study of misoprostol vs sucralfate and placebo in the prevention of aspirin-induced gastric and duodenal ulceration. Am J Gastroenterol 1988;839:143-6.

14. Lanza FL, Fakouhi A, Rubin A, et al. A double-blind, placebocontrolled comparison of the efficacy and safety of $50 \mathrm{mcg}, 100 \mathrm{mcg}$ and $200 \mathrm{mcg}$ of misoprostol, q.i.d., in the prevention of ibuprofeninduced gastric and duodenal mucosal lesions and symptoms. Am J Gastroenterol 1989;84:633-6.

15. Jiranek GC, Kimmey MD, Saunders DR, et al. Misoprostol reduces gastroduodenal injury from one week of aspirin. An endoscopic study. Gastroenterology 1989;96:656-61.

16. Graham DY, Agrawal NM, Roth SH. Prevention of NSAID-induced gastric ulcer with misoprostol: Multicentre, double-blind placebocontrolled trial. Lancet 1988;ii:1277-80.

17. Graham DY, White RH, Moreland W, et al., and the Misoprostol Study Group. Duodenal and gastric ulcer prevention with misoprostol in arthritis patients taking NSAIDs. Ann Intern Med 1993;119:25762.

18. Agrawal NM, Roth SH, Graham DY, et al. Misoprostol compared with sucralfate in the prevention of nonsteroidal anti-inflammatory drug-induced gastric ulcer in randomized control trial. Ann Intern Med 1991;115:195-200.

19. Raskin JB, White RH, Jackson JE, et al. Misoprostol dosage in the prevention of nonsteroidal anti-inflammatory drug-induced gastric and duodenal ulcers: A comparison of three regimens. Ann Intern Med 1995;123:344-50.

20. Bardhan KD, Bjarnason I, Scott DL, et al. The prevention and healing of acute nonsteroidal anti-inflammatory drug-associated gastroduodenal mucosal damage by misoprostol. Br J Rheumatol 1993;32: 990-5.

21. Elliott SL, Yeomans ND, Buchanan RR, et al. Efficacy of 12 months misoprostol as prophylaxis against NSAID-induced gastric ulcers. A placebo-controlled trial. Scand J Rheumatol 1994;23:171-6.

22. Raskin JB, White RH, Jaszewski R, et al. Misoprostol and ranitidine in the prevention of NSAID-induced ulcers: a prospective, doubleblind, multicenter study. Am J Gastroenterol 1996;91:223-7.

23. Koch M, Dezi A, Ferrario F, et al. Prevention of nonsteroidal antiinflammatory drug-induced gastrointestinal mucosal injury. Arch Intern Med 1996;156:2321-2.

24. Ekstrom P, Carling L, Wetterhus S, et al. Prevention of peptic ulcer and dyspeptic symptoms with omeprazole in patients receiving continuous nonsteroidal anti-inflammatory drug therapy. A Nordic multicentre study. Scand J Gastroenterol 1996;31:753-8.

25. Hawkey CJ, Karrasch JA, Szczepa' L, et al. Omeprazole for ulcers associated with nonsteroidal anti-inflammatory drugs. N Eng J Med 1998;338:727-34.

26. Yeomans ND, Tulassay Z, Juhasz L, et al. A comparison of omeprazole with ranitidine for ulcers associated with nonsteroidal antiinflammatory drugs. N Engl J Med 1998;338:719-26.

27. Ehsannulah RSB, Page MC, Tildesley G, et al. Prevention of gas- 
troduodenal damage induced by nonsteroidal anti-inflammatory drugs: Controlled trial of ranitidine. Br Med J 1988;297:1017-21

28. Robinson MG, Griffin JW, Bowers J, et al. Effect of ranitidine on gastroduodenal mucosal damage induced by nonsteroidal anti-inflammatory drugs. Dig Dis Sci 1989;34:424-8.

29. Lanza FL. A review of gastric ulcer and gastroduodenal injury in normal volunteers receiving aspirin and other nonsteroidal anti-inflammatory drugs. Scand J Gastroenterol 1989;24:24-31.

30. Cardoc-Davies TH. Nonsteroidal anti-inflammatory drugs, arthritis and gastrointestinal bleeding in elderly patients. Age Aging 1984;13: 295-8.

31. Langman MJS, Morgan L, Worrall A. Use of anti-inflammatory drugs by patients admitted with small or large bowel perforation and hemorrhage. Br Med J 1985;290:347-9.

32. Sommerville K, Faulkner G, Langham M. Nonsteroidal anti-inflammatory drugs and bleeding peptic ulcer. Lancet 1986;1:462-4.

33. Collier DSTJ, Pain JA. Nonsteroidal anti-inflammatory drugs and peptic ulcer perforation. Gut 1985;26:359-63.

34. Walt R, Katschinski B, Logan R, et al. Rising frequency of ulcer perforation in older people in the United Kingdom. Lancet 1986;1: 489-92.

35. Beard K, Walker AM, Perera DR, et al. Nonsteroidal anti-inflammatory drugs and hospitalization for gastroesophageal bleeding in the elderly. Arch Intern Med 1987;147:1621-3.

36. Armstrong CP, Blower AL. Nonsteroidal anti-inflammatory drugs and life threatening complications of peptic ulceration. Gut 1987;28: 527-32.

37. Levy M, Miller DR, Kaufman DW, et al. Major upper gastrointestinal bleeding. Relation to the use of aspirin and other non-narcotic analgesics. Arch Intern Med 1988;148:281-5.

38. Steering Committee of the Physicians Health Study Research Group. Final report on the aspirin component of the ongoing health study. N Engl J Med 1989;321:129-35.

39. Slattery J, Warlow CP, Shorrock CJ, et al. Risks of gastrointestinal bleeding during secondary prevention of vascular events with aspirin-analysis of gastrointestinal bleeding during the UK-TIA trial. Gut 1995;37:509-11.

40. Naschitz JE, Yeshurun B, Odeh M, et al. Overt gastrointestinal bleeding in the course of chronic low dose aspirin administration for secondary prevention of arterial occlusive disease. Am J Gastroenterol 1990;85:408-11.

41. Kurata JH, Abbey DE. The effect of chronic aspirin use on duodenal and gastric ulcer hospitalizations. J Clin Gastroenterol 1990;12:260-6.

42. Griffin MR, Ray WA, Schaffner W. Nonsteroidal anti-inflammatory drug use and death from peptic ulcer in elderly patients. Ann Intern Med 1988;109:359-63.

43. Griffin MR, Piper JM, Daugherty JR, et al. Nonsteroidal anti-inflammatory drug use and increased risk for peptic ulcer disease in elderly person. Ann Intern Med 1991;114:257-63.

44. Piper JM, Ray WA, Daugherty JR, et al. Corticosteroid use in peptic ulcer disease; role of nonsteroidal anti-inflammatory drugs. Ann Intern Med 1991;114:735-40.

45. Sharr RJ, Ray WA, Daugherty JR, et al. Concurrent use of nonsteroidal anti-inflammatory drugs and oral anticoagulants places elderly persons at high risk for hemorrhagic peptic ulcer disease. Arch Intern Med 1993;153:1665-70.

46. Allison MC, Howatson AG, Torrance CJ, et al. Gastrointestinal damage associated with the use of nonsteroidal anti-inflammatory drugs. N Engl J Med 1992;327:749-54.

47. Carson JL, Strom BL, Morse ML, et al. The relative gastrointestinal toxicity of nonsteroidal anti-inflammatory drugs. Arch Intern Med 1987;147:1054-9.

48. Beardon PH, Brown SV, McDevitt TG. Gastrointestinal events in patients prescribed nonsteroidal anti-inflammatory drugs. A controlled study using record likage in Tayside. Q J Med 1989;71:497505 .

49. Bloom BS. Risk and cost of gastrointestinal side effects associated with nonsteroidal anti-inflammatory drugs. Arch Int J Med 1989;149: $1019-22$.

50. LaProte JR, Carne X, Vidal X, et al. Upper gastrointestinal bleeding in relation to previous use of analgesics and nonsteroidal anti-inflammatory drugs. Lancet 1991;337:85-9.

51. Garcia-Rodriguez LA, Jick H. Risk of upper gastrointestinal bleeding and perforation associated with individual nonsteroidal anti-inflammatory drugs. Lancet 1994;343:769-72.

52. Langman MJS, Weil J, Wainwright P, et al. Risks of bleeding peptic ulcer associated with individual nonsteroidal anti-inflammatory drugs. Lancet 1994;343:1075-8.

53. Henry D, Dobson A, Turner C. Variability in the risk of major gastrointestinal complications from nonaspirin anti-inflammatory drugs. Gastroenterology 1993;105:1078-88.

54. Garcia Rodriguez LA, Cattaruzzi C, Grazia Troncon M, et al. Risk of Hospitalization for upper gastrointestinal tract bleeding associated with ketorolac, other nonsteroidal anti-inflammatory drugs, calcium antagonists, and other hypertensive drugs. Arch Intern Med 1998; 158:33-39.

55. Jenner PN. A 12 month post-marketing surveillance study of nabumetone. A preliminary report. Drugs 1990;40:38-42.

56. Stoehmann I, Fedder M, Zeidler H. German drug monitoring studies with nabumetone. Drugs 1990;40:38-44.

57. Willkens RF. An overview of the long-term safety experience with nabumetone. Drugs 1990;40(S15):34-37.

58. Benhamou CL. Large scale open trials with etodolac (Lodine) in France: An assessment of safety. Rheumatol Int 1990;10(suppl):2934.

59. Schattenkirchner M. An updated safety profile of etodolac in several thousand patients. Eur J Rheumatol Inflam 1990;10:56-65.

60. Lanza FL. Gastrointestinal toxicity of new NSAIDs. Am J Gastroenterol 1993;88:1318-23.

61. Roth SH, Tindall EA, Jain AK, et al. A controlled study comparing the effects of nabumetone, ibuprofen, and ibuprofen plus misoprostol on the upper gastrointestinal tract mucosa. Arch Intern Med 1993; 153:2565-71.

62. Porro GB, Montrone F, Petrillo M, et al. Gastroduodenal tolerability of nabumetone versus naproxen in the treatment of rheumatic patients. Am J Gastroenterol 1995;90:1485-8.

63. Roth SH, Bennett R, Caldron P, et al. A long term endoscopic evaluation of patients with arthritis treated with nabumetone vs naproxen. J Rheumatol 1994;21:1118-23.

64. Chalmer TC, Berrier J, Hewitt R, et al. Meta-analysis of randomized controlled trials as a method of estimating rare complications of nonsteroidal anti-inflammatory drug therapy. Aliment Pharmacol Ther 1988;2(supp 1):9-26.

65. Scheiman JM, Behier EM, Loeffler KM, et al. Omeprazole ameliorates aspirin-induced gastroduodenal injury. Dig Dis Sci 1994;39:97103.

66. Levine LR, Cloud ML, Enas NH. Nizatodine prevents peptic ulceration in high risk patients taking nonsteroidal anti-inflammatory drugs. Arch Intern Med 1993;153:449-54.

67. Simon B, Muller P. Nizatidine in therapy and prevention of nonsteroidal anti-inflammatory drug-induced gastroduodenal ulcer in rheumatic patients. Scand J Gastroenterol 1994;206:25-8.

68. Taha AS, Hudson N, Hawkey CJ, et al. Famotidine for the prevention of gastric and duodenal ulcers caused by nonsteroidal anti-inflammatory drugs. N Engl J Med 1996;334:1435-9.

69. Hudson N, Taha AS, Russell RI, et al. Famotidine for healing and maintenance in nonsteroidal anti-inflammatory drug-associated gastroduodenal ulceration. Gastroenterology 1997;112:1817-22.

70. ten Wolde S, Dijkmans BA, Janssen M, et al. High-dose ranitidine for the prevention of recurrent peptic ulcer disease in rheumatoid arthritis patients taking NSAIDs. Aliment Pharmacol Ther 1996;10:347-51.

71. McCarthy DM. Sucralfate. N Engl J Med 1991;325:1017-25.

72. Miglioli M, Porro GB, Vaira D, et al. Prevention with sucralfate gel of NSAID-induced gastroduodenal damage in arthritic patients. Am J Gastroenterol 1996;91:2367-71.

73. Lanza FL, Royer GL, Nelson RS. An endoscopic evaluation of the effects of aspirin, buffered aspirin and enteric-coated aspirin on the gastric and duodenal mucosa. A controlled study. N Engl J Med 1980;303:136-8.

74. Silvoso GR, Ivey KJ, Butt JH, et al. Incidence of gastric lesions in patients with rheumatic disease on chronic aspirin therapy. Ann Intern Med 1979;91:517-20.

75. Lockard OO, Ivey KJ, Butt JH, et al. The prevalence of duodenal lesions in patients with rheumatic disease on chronic aspirin therapy. Gastrointest Endosc 1980;26:5-7.

76. Kelly JP, Kaufman DW, Jurgelon JM. Risk of aspirin-associated 
major upper-gastrointestinal bleeding with enteric-coated or buffered product. Lancet 1996;348:1413-6.

77. Bianchi Porro G, Montrone F, Petrillo M, et al. Sulglycotide in the prevention of nonsteroidal anti-inflammatory drug-induced gastroduodenal mucosal injury. A controlled double-blind, double-dummy, randomized endoscopic study vs. placebo in rheumatic patients. Scand J of Gastroenterol 1993;28:875-8.

78. Rodriguez de la Serna A, Diaz-Rubio M. Multicenter clinical trial of zinc acexamate in the prevention of nonsteroidal anti-inflammatory drug induced gastroenteropathy. Spanish Study Group on NSAID-Induced Gastroenteropathy Prevention. J Rheumatol 1994;21:927-33.

79. Huskisson EC, Ghozian R, Kurthen R, et al. A long-term study to evaluate the safety and efficacy of meloxicam therapy in patients with rheumatoid arthritis. Br J Rheumatol 1996;35(suppl 1):29-34.

80. Lanza FL, Simon T, Quan H, et al. Selective inhibition of cyclooxygenase-2 (COX-2) with MK-0966 (250 mg q.d.) is associated with less gastroduodenal damage than aspirin (ASA) $650 \mathrm{mg}$ q.i.d. or ibuprofen (IBU) $800 \mathrm{mg}$ t.i.d. Gastroenterology 1997;112:A194.

81. Lanza FL, Rack MF, Callison DA, et al. A pilot endoscopic study of the gastroduodenal effects of SC-58635, a novel COX-2-selective inhibitor. Gastroenterology 1997;112:A194.

82. Lancaster-Smith MJ, Jaderberg ME, Jackson DA. Ranitidine in the treatment of nonsteroidal anti-inflammatory drug associated with gastric and duodenal ulcers. Gut 1991;32:69-75.

83. Tildesley G, Ensanullah RS, Wood JR. Ranitidine in the treatment of gastric and duodenal ulcers associated with nonsteroidal anti-inflammatory drugs. Br J Rheumatol 1993;32:474-8.

84. Walan A, Bader JP, Classen M, et al. The effect of omeprazole and ranitidine on ulcer healing and relapse rates in patients with benign gastric ulcer. N Engl J Med 1989;320:59-75.

85. Bank S, Blumstein M, Greenberg RE, et al. Efficacy of famotidine in the healing of active benign gastric ulceration: comparison of nonsteroidal anti-inflammatory- or aspirin-induced gastric ulcer and idiopathic gastric ulceration. Long Island Jewish Medical Center AcidPeptic Study Group. Clinical Therapeutics 1993;15:36-45.

86. Jaszewski R, Calzada R, Dhar R. Persistence of gastric ulcers caused by plain aspirin or nonsteroidal anti-inflammatory agents in patients treated with a combination of cimetidine, antacids and enteric-coated aspirin. Dig Dis Sci 1989;34:1361-4.

87. Laine L, Marin-Sorenson M, Weinsein WM. Nonsteroidal anti-inflammatory drug-associated gastric ulcers do not require Helicobacter pylori for their development. Am J Gastroenterol 1992;87:13981402.

88. Herebach B, Raoul JL, Bretagne JF, et al. Helicobacter pylori: A risk of severity factor of nonsteroidal anti-inflammatory drug-induced gastropathy. Gut 1992;33:1608-11.

89. Kim JG, Graham DY. Helicobacter pylori infection and development of duodenal ulcer in arthritic patients receiving chronic NSAID therapy. The Misoprostol Study Group. Am J Gastroenterol 1994;89: 203-7.

90. Goggin PM, Collins DA, Jazrawi RP, et al. Prevalence of Helicobacter pylori infection and its effect on symptoms and non-steroidal anti-inflammatory drug induced gastrointestinal damage in patients with rheumatoid arthritis. Gut 1993;34:1677-80.

91. Taha AS, Dahill S, Nakshabendi I, et al. Duodenal histology, ulceration, and Helicobacter pylori in the presence or absence of nonsteroidal anti-inflammatory drugs. Gut 1993;34:1162-6.

92. Li EK, Sung JJ, Suen R, et al. Helicobacter pylori infection increases the risk of peptic ulcers in chronic users of non-steroidal anti-inflammatory drugs. Scand J Rheumatol 1996;25:42-6.

93. Bianchi Porro G, Parente F, Imbesi V, et al. Role of Helicobacter pylori in ulcer healing and recurrence of gastric and duodenal ulcers in long-term NSAID users. Response to omeprazole dual therapy. Gut 1996;39:22-6.

94. Chan FKL, Sung JJY, Chung SCS, et al. Randomised trial of eradication of Helicobacter pylori before nonsteroidal anti-inflammatory drug therapy to prevent peptic ulcers. Lancet 1997;350:975-9.

95. Cullen DJE, Hawkey GM, Greenwood DC, Humphreys H, Shepherd V, Logan RFA, Hawkey CJ. Peptic ulcer bleeding in the elderly: Relative roles of Helicobacter pylori and nonsteroidal anti-inflammatory drugs. Gut 1997;41:459-62.

96. Madhok R, Mackenzie JA, Lee FD, et al. Small bowel ulceration in patients receiving NSAIDs for rheumatoid arthritis. Q J Med 1986; 58:53-8.

97. Lang J, Price AB, Levi AJ, et al. Diaphragm disease: the pathology of nonsteroidal anti-inflammatory drug induced small intestinal strictures. J Clin Pathol 1988;41:516-26.

98. Bjarnason I, Price AB, Zanelli G, et al. Clinico-pathological features of NSAID induced small intestinal strictures. Gastroenterology 1988; 94:1070-74.

99. Hershfield NB. Endoscopic description of diaphragm disease induced by non-steroidal anti-inflammatory drugs. Gastrointest Endosc 1992; $38: 267$.

100. Morris AJ, Madhock R, Sturrock RD, et al. Enteroscopic diagnosis of small bowel ulceration in patients receiving nonsteroidal anti-inflammatory drugs. Lancet 1991;331:520.

101. Bjarnason I, Hayllar J, Macpherson AJ, et al. Side effects of nonsteroidal anti-inflammatory drugs on the small and large intestine in humans. Gastroenterology 1993;104:1832-47.

102. Bjarnason I, Williams P, Smethrust P, et al. The effects of NSAIDs and prostaglandins on the permeability of the human small intestine. Gut 1986;27:1292-7.

103. Jenkins RT, Rooney PJ, Jones DB, et al. Increased intestinal permeability in patients with rheumatoid arthritis: A side effect of oral nonsteroidal anti-inflammatory drug therapy. Br J Rheumatol 1987; 26:103-7.

104. Reuter BK, Davies NM, Wallace JL. Nonsteroidal anti-inflammatory drug enteropathy in rats: role of permeability, bacteria, and enterohepatic circulation. Gastroenterology 1997;112:109-17.

105. Bjarnason I, Williams P, So A, et al. Intestinal permeability and inflammation in rheumatoid arthritis; effects of nonsteroidal antiinflammatory drugs. Lancet 1984;2:1171-4.

106. Bjarnason I, Zanelli G, Smith T, et al. Non-steroidal anti-inflammatory drug induced inflammation in humans. Gastroenterology 1987; 93:480-9.

107. Gibson GR, Whitacre EB, Ricotti CA. Colitis induced by nonsteroidal anti-inflammatory drugs. Arch Intern Med 1992;152:625-32.

108. Tanaka M, Mazzoleni G, Ridell RH. Nonsteroidal anti-inflammatory drugs as a possible cause of collagenous colitis. Gastroenterology 1991;101:A845.

109. Cuvelier C, Barbatis C, Mielants H, et al. Histopathology of intestinal inflammation related to reactive arthritis. Gut 1987;28:394-401.

110. Charuzi I, Ovnat A, Zirkin H, et al. Ibuprofen and benign cecal ulcer. J Rheumatol 1985;12:188-9.

111. Uribe A, Johansson C, Scezak P, et al. Ulceration of the colon associated with naproxen and acetylsalicylic acid treatment. Gastrointest Endosc 1986;32:242-4.

112. Bravo AC, Lowman RM. Benign ulcer of sigmoid colon. Radiology 1968;90:113-5.

113. Walls J, Bell D, Schora W. Rectal bleeding and indomethacin. $\mathrm{Br}$ Med J 1968;1:52.

114. Levy N, Gaspar E. Rectal bleeding and indomethacin suppositories. Lancet 1975;305:577.

115. Lanthier P, Detry R, Debongnie JC, et al. Solitary rectal lesions due to suppositories containing acetylsalicylic acid and paracetamol. Gastroentrol Clin Biol 1987;11:250-3.

116. Wilson RG, Smith AN, MacIntyre IMC. Complications of diverticular disease and nonsteroidal anti-inflammatory drugs. A prospective study. Br J Surg 1990;77:1103-4.

117. Campbell K, Steele RJC. Non-steroidal anti-inflammatory drugs and complicated diverticular disease; a case-control study. Br J Surg 1991;78:190-1.

118. Foutch PG. Diverticular bleeding: Are nonsteroidal anti-inflammatory drugs risk factors for hemorrhage and can colonoscopy predict outcome for patients? Am J Gastroenterol 1995;90:1779-84.

119. Kaufman HJ, Taubin HL. NSAID activate quiescent inflammatory bowel disease. Ann Intern Med 1987;107:513-6.

120. Rampton DS, McNeil NI, Sarner M. Analgesic ingestion and other factors preceeding relapse in ulcerative colitis. Gut 1983;24:187-9.

121. Evans JMM, McMahon AD, Murray FE, et al. Nonsteroidal antiinflammatory drugs are associated with emergency admission to hospital for colitis due to inflammatory bowel disease. Gut 1997;40: $619-22$. 